\title{
DE DISCURSOS COLONIALES Y TEXTOS ANDINOS. A PROPÓSITO DE GENTE DE LA TIERRA DE GUERRA...*
}

\author{
OF COLONIAL DISCOURSES AND ANDEAN TEXTS. IN RELATION \\ TO GENTE DE LA TIERRA DE LA GUERRA...
}

\author{
José Luis Martínez C. ${ }^{1}$
}

\begin{abstract}
A un costado de un viejo camino en la quebrada de Humahuaca (Argentina), en un lugar conocido como Sapagua, hay una gran roca que tiene prácticamente toda su superficie plana cubierta de grabados, hechos probablemente por muchas generaciones sucesivas de pobladores andinos, desde antes de la llegada de los incas a la zona (Aschero 1999). Lo interesante de este sitio de arte rupestre es que una parte de la roca tiene representaciones de escenas de enfrentamientos violentos entre personajes que podemos reconocer como jinetes europeos y combatientes indígenas que, a pie, se oponen a ellos con arcos y flechas. Se trata de un tema colonial de amplia difusión en el sur andino (Hernández Llosas 2006; Martínez y Arenas 2009). En otra pared de piedra, ahora en el río Loa (norte de Chile), a las imágenes de violencia y confrontación entre andinos y españoles se les superpone la de una iglesia católica, con su campanario y cruz (Gallardo et al. 1999). Podemos suponer que los creadores de las imágenes que están en el río Loa fueron los mismos, porque se trata de la misma técnica y estilo; gentes que representaron sucesivamente episodios y procesos de la vida colonial que se iniciaba en estas tierras. Los fechados más probables para todas esas manifestaciones visuales, las de Humahuaca, como las de Atacama, son de la segunda mitad del siglo XVI o de inicios del siglo XVII.

Se trata de espacios que los habitantes del altiplano de Lípez (esos que la administración colonial llamó lipes) recorrieron una y otra vez; lugares en los cuales probablemente también vivieron e interactuaron con los otros grupos humanos locales. No puedo afirmar que los autores de las representaciones hayan sido gente del altiplano de Lípez, pero es muy probable que, conociendo los fuertes lazos establecidos entre unos y otros grupos, sí hayan participado
\end{abstract}

en su confección, o al menos en los rituales que se realizaban periódicamente para activarlos.

¿Por qué traigo esto a colación, a propósito de los comentarios sobre el libro Gente de la Tierra de Guerra? Porque esta ha sido una de mis respuestas a los problemas epistemológicos, teóricos y metodológicos que enfrenté para escribir este libro y que con mucha claridad exponen y discuten los comentarios de mis colegas Frank Salomon, Guillaume Boccara, Francisco Gil García y Vivian Gavilán Vega. La búsqueda de materiales andinos a través de los cuales los hombres y mujeres del tiempo colonial hicieron circular sus pensamientos, sus memorias, sus relatos de lo cotidiano, sin tener que acudir a los registros documentales escritos, ha sido mi preocupación central en estos años, una vez terminado el libro.

Tal como lo señaló Frank Salomon (2013, en este número) en su comentario, Gente de la Tierra de Guerra se inició con una constatación, la de la escasez documental; y con una frustración: la de concluir que en esos pocos documentos lo que dijeran los habitantes de Lípez sobre sí mismos, acerca de sus prácticas sociales y económicas, de sus modos de vida y de sus divinidades, estaba ausente. Siempre había otros que hablaban por ellos (que escribían, para ser más precisos); gente que incluso sin conocer el lugar, los describía, los clasificaba. Un pequeño texto, que incluí en el capítulo final del libro, es expresivo de esta ausencia de una palabra propia, de una voz que hable en sus propios términos. Algunos caciques de lipes intentaron apelar a las tasas impuestas y lo que quedó de sus argumentos fue lo siguiente:

... sabed que por parte de los caçiques y prinçipales e yndios del repartimiento de

* Réplica a los comentarios críticos y de debate de Frank Salomon, Guillaume Boccara, Francisco M. Gil García y Vivian Gavilán Vega al libro Gente de la Tierra de Guerra. Los Lipes en las Tradiciones Andinas y el Imaginario Colonial. DIBAM-Fondo Editorial Pontificia Universidad Católica del Perú, Santiago-Lima, 2011.

1 Centro de Estudios Culturales Latinoamericanos, Universidad de Chile, Santiago, Chile. jomarcer@u.uchile.cl 
los lipis (...) fue presentada ante mi vna informaçion fecha en el asyento de minas de Potosi en diez y siete dias de noviembre del año pasado de quinientos e çinquenta e ocho (...) por la qual paresçe que los dichos yndios lipis se agrauian diziendo que a causa de ser ellos vros y no tener en su tierra mas que quinoa y sal y algunas papas que vale poca cosa... (subrayados y negritas son mías) ${ }^{1}$.

"Parece" que se agravian, el escribano duda de la afirmación de las autoridades tradicionales; "dicen ser" urus, otra afirmación que queda puesta bajo una interrogación; y aun en la descripción de la pobreza productiva de sus tierras ("nada más que" quinua, sal y papas) puede advertirse un cierto tono peyorativo.

Así, el de la escritura no fue, claramente, un espacio al que tuvieran acceso los habitantes del altiplano meridional; lo que puede marcar importantes diferencias con otros lugares del mismo altiplano y de las sociedades andinas, en las que es posible encontrar piezas documentales tan valiosas como el Memorial que dirigieron los señores de Charkas al rey (Platt et al. 2006), o la abundante correspondencia que dejó Diego Chambilla, capitán de la mit'a en Potosí (Medinacelli e Inch 2010; Murra 1978), por mencionar algunos de los documentos publicados en estos últimos años. Pero a pesar de esa condición de ausencia de una voz propia presente en la escritura, la obligación ética de la antropología y de la etnohistoria que menciona Guillaume Boccara (2013, en este número), de no hablar por, sino de posibilitar que sean los propios dominados los que hablen de sí mismos, sigue en pie, aun no teniendo documentos escritos donde encontrarlos. ¿Qué hacer entonces? En ese libro, tímidamente porque no conocía aún todo el enorme material disponible, me atreví a sugerir que una de las tareas de los etnohistoriadores es la de buscar los espacios no europeos en los cuales pudieron haber circulado con mayor libertad (o con menor restricción) lo que podríamos llamar las palabras andinas, las voces propias. Aquellas que no respondían a los discursos de poder, a las prácticas de dominación ni a la imposición directa de los saberes y las epistemes de control a los que hace referencia Guillaume Boccara. Aquellos espacios no europeos, precisamente, permitirían mostrar que la malla de Supermán, a la que hace alusión Salomon, en este caso estaba al menos apolillada, puesto que esos relatos no escritos alfabéticamente parecieran haber seguido circulando al interior mismo del sistema colonial. Ya volveré sobre los problemas que se abren en esta perspectiva.

Y el tema de los espacios de la escritura me lleva a un segundo punto. Efectivamente, Gente de la Tierra de Guerra se escribió en un contexto muy complejo de debates teóricos, de intentos de clausurar metodológicamente los supuestos que habían permitido iniciar una búsqueda de nueva documentación para conocer a las sociedades andinas prehispánicas y coloniales. Tanto Frank Salomon como Guillaume Boccara han aludido a las luchas teóricas y epistemológicas que sacudieron a la mayoría de las ciencias sociales y las humanidades en las últimas décadas del siglo XX y a inicios del XXI. Y Vivian Gavilán Vega (2013, en este número) expone con fuerza algunas de las tensiones conceptuales que siguen cruzando nuestros análisis. Salomon incluso hace mención a las "cicatrices" que (nos) dejaron las "guerras de teorías". Tengo que agradecerle a todos haber centrado sus comentarios en esos aspectos, que exceden largamente el caso concreto de los lipes y que guardan relación con los quehaceres disciplinarios, ya sea en los Andes, en el mundo mapuche o en otros lugares. Estoy de acuerdo en que hay que poner la lectura de este libro en ese contexto. Se trata de un trabajo que tomó posiciones y que fue escrito haciéndome cargo de las discusiones.

Si bien coincido con gran parte de lo expresado por Guillame Boccara sobre las tensiones que se derivan de las diferentes posiciones que unos y otros asumimos en esos debates, creo que es necesario puntualizar algunos aspectos que pueden tener una relación más específica con la situación de los estudios etnohistóricos en el área andina, porque probablemente no ocurrió de igual manera en otras áreas culturales. Y que tiene mucho que ver con el libro. Me refiero a que las "guerras de teorías" impusieron distintos elementos para el debate, pero en el caso andino al menos uno tuvo un gran impacto: la sospecha sobre la escritura, entendida ya no como un lugar en el cual encontrar testimonios andinos (esta fue la gran revolución documental que impulsó John Murra), sino únicamente como un espacio de poder, autorreferido, en el que los documentos no hablaban de las prácticas ni de las experiencias de los sujetos, sino básicamente (casi exclusivamente según algunos) de la experiencia 
unilateral de construir la "ciudad letrada" desde el control de la escritura. Esto provocó una suerte de clausura metodológica (junto a una gran angustia, es necesario reconocerlo), y abrió la puerta a nuevas interrogantes, puesto que las técnicas de lectura iniciales de la etnohistoria, que incluían el "pasar a través del espejo" (Wachtel 1976) o aplicar los "filtros" (Rostworowski 1983), interrogando de nuevas maneras a las visitas y otros documentos en los que aparecían testimonios de andinos resultaban insuficientes ante los embates y desafíos teóricos ${ }^{2}$. Me parece que el libro de Franklin Pease, Las Crónicas y los Andes (1995), fue uno de los más importantes intentos de ese momento para proponer algunas respuestas teóricas y metodológicas. El otro fue la búsqueda de nuevos tipos de fuentes andinas, tal como lo propuso el mismo Murra (2002 [1973]) en su trabajo sobre las etnocategorías de un khipu estatal, y que fue seguido por otros colegas posteriormente, entre los que se cuentan los valiosos trabajos del mismo Frank Salomon.

Dejando de lado algunas de las posiciones más extremas, que negaban cualquier posibilidad de conocer a las sociedades andinas a través de los documentos escritos y que proclamaron asimismo la imposibilidad de acceder a su pasado, hay varios aspectos que sí me parece se deben rescatar de la revalorización de la escritura como acto y espacio de poder. Porque es claro, a estas alturas, que ella conlleva un conjunto de determinaciones que anteriormente no habían sido consideradas. La linealidad de la escritura, que metaforiza una determinada concepción epistemológica del tiempo (lineal, continuo, con un antes y un después); y una determinada cardinalidad (norte, sur; abajo/ arriba), que están a la base de las formas de ordenar los relatos y las secuencias de desplazamientos de los europeos por el continente, es tal vez una de las más evidentes. Lo que los trabajos etnohistóricos previos no habían tomado en consideración era que esas determinantes tuvieran igualmente implicancias en la redacción de muchos de los documentos coloniales, puesto que no solo fijaron los relatos orales andinos en versiones que pretendían ser únicas, sino que también exigieron un reordenamiento de los mismos, con un principio -un antes- y un desarrollo posterior -el después-, contrario a las formas de organizar los tiempos de los relatos andinos. Y este es sólo un ejemplo. En Gente de la Tierra de Guerra discuto varios otros, por lo que no me extenderé aquí.
Dicho esto, me parece que lo que plantea Frank Salomon al inicio de sus comentarios, respecto de las "oscuridades" que enfrentamos para avanzar en el conocimiento de los grupos humanos en el período inmediatamente anterior a la invasión europea de los siglos XV y XVI, y el del período colonial que ellos instauraron, es una muy fina e ilustradora analogía que resume, precisamente, aquello que traté de señalar anteriormente: que hoy la tarea de los etnohistoriadores sigue siendo la de la comprensión de las sociedades tal como ellas funcionaron bajo los distintos sistemas de dominación a los que se vieron sometidas, pero que para hacerlo no podemos descuidar las categorías epistémicas y cognitivas que cada sociedad o grupo dominante impuso sobre ellas. El intento del libro que estamos comentando fue mostrar que los españoles no fueron los únicos dominadores que impusieron sus discursos y maneras de clasificar a los habitantes de los lipes, sino que también los hicieron -con sus propias categorías-los incas y, antes que ellos, los aymaras.

En el seno de ese debate subyace, también, una cuestión metodológica que me parece medular, y comparto la lectura que hacen Frank Salomon y Vivian Gavilán respecto de que Gente de la Tierra de Guerra hace una propuesta concreta al respecto. En cierto sentido, el libro se propone como una etapa de investigación, imprescindible desde mi punto de vista; como un momento de la construcción de conocimiento sobre las sociedades coloniales, que debe ser continuada con otros materiales y estrategias, entre las cuales la interdisciplinariedad y la incorporación de otras voces para ir construyendo textos más multivocales, como lo sugiere Boccara, me parecen imprescindibles. Así, me parece importante redimensionar la tarea emprendida en Gente de la Tierra de Guerra: no se trata de dedicarse, como señala Boccara, al "análisis crítico del orientalismo" que atraviesa a las fuentes coloniales; ni de sustituir un objeto de estudio ("el comportamiento, la organización socioeconómica") de las sociedades indígenas, por otro nuevo "la cultura concebida como discurso", como lo puntualiza Salomon. En ningún caso debe pensarse que el estudio de una sociedad colonial puede quedar restringido al análisis de las formaciones discursivas que operaron sobre ella y contribuyeron a su dominación, puesto que se trata de una etapa de la investigación y no de un fin en sí mismo. Pero de igual manera quiero ser enfático en señalar que me parece que es también inevitable hacerlo. 
Los comentarios que me han hecho mis colegas son de diferente índole. Guillaume Boccara se pronuncia por una cuestión general: por el estatuto de la etnohistoria, sus enfoques recientes y las demandas que debemos enfrentar, teórica y éticamente, quienes seguimos investigando en este campo disciplinario. Frank Salomon, por su parte, propone una discusión acerca de las consecuencias teóricas y metodológicas de aplicar algunas de las proposiciones de Michel Foucault al estudio de las sociedades andinas, inclinándose más por una aproximación bakhtiniana. Francisco Gil García (2013, en este número) hace certeras observaciones respecto de las lecturas que se pueden hacer del material documental sobre los lipes del siglo XVI. Y finalmente, Vivian Gavilán recoge el desafío de discutir sus propias experiencias sobre los aymaras vecinos de los lipes a la luz de algunas de las propuestas de este libro. Me veo obligado a declarar, de entrada, que comparto la mayoría de las observaciones que se me formulan, pero responder o dialogar con todas las sutiles y apasionantes observaciones que hizo cada uno de ellos me llevaría a intentar escribir un trabajo más extenso que el que puedo hacer aquí. Por lo que, en lo que sigue, intentaré únicamente ofrecer algunos aportes a las discusiones que ellos mismos proponen.

El debate planteado por Boccara gira en torno a las posibilidades de hacer etnohistoria, hoy; desde dónde hacerlo y con quiénes. Él establece con claridad una suerte de parteaguas ético, político y también teórico; entre escribir para perpetuar la dominación colonial sobre las sociedades indígenas, donde se ubican los que escriben las historias sobre los indígenas; y aquellos que asumen que la etnohistoria aún puede ser parte de una acción liberadora, que escriben historias indígenas. Establecida esta separación, surge, entre otros, el problema o el desafío de la construcción de las "historias del futuro sobre unas bases realmente interculturales". En su apasionada y apasionante reflexión propone, también, la necesidad de repensar conceptos (y usos) de cuestiones tales como la memoria o el pasado, que hoy debieran ser entendidos en claves emancipadoras. ¿Las memorias de quiénes? ¿Qué pasados? ¿Quiénes hablan y construyen saberes? son algunos de los temas propuestos. Estos son parte de los nuevos desafíos que Boccara propone.

Comparto con él que estos son algunos de los temas que debemos discutir permanentemente. Los qeros, esos vasos de madera que fueron hechos a partir del siglo XVI, con preciosas escenas en las que se relataron visualmente algunos antiguos mitos fundacionales del Tawantinsuyu, o se pintaron momentos de la rebelión de Manqho Inka contra el dominio español, plantean con fuerza el tema de cómo las sociedades andinas coloniales se vieron obligadas a repensarse y representarse, construyendo nuevos relatos acerca de su pasado y elaborando nuevas memorias acerca de ellos mismos. Memorias, pasados, discursos, toponimias, prácticas y luchas sociales, son problemas que han enfrentado permanentemente todas las sociedades y es por eso que sigue siendo una tarea ineludible de los etnohistoriadores abordar su discusión.

Hay en este punto, sin embargo, un aspecto en el que me gustaría detenerme y que fue planteado hace bastante tiempo por Frank Salomon (1994), ¿de qué tipos de memoria y de pasados estamos hablando? ¿Es, solamente, una cuestión de entender que el pasado está indisolublemente vinculado al presente, como lo plantea Guillaume Boccara? ¿De definir quién tiene la legitimidad para recordar o determinar cuándo empieza el pasado para una determinada sociedad? ¿O de hacerse parte de los esfuerzos de las comunidades andinas de construir relatos propios que den cuenta de las tensiones de su presente, tal como lo muestra Vivian Gavilán? Son cuestiones centrales y comparto con Boccara este planteamiento, pero lo que planteó Salomon va más allá. Cuando una sociedad construye sus memorias y construye sus pasados, ¿desde dónde lo hace? ¿A partir de qué estructuras epistemológicas? Lo que Frank Salomon planteó es que al intentar responder por el pasado, preguntados por los europeos, los andinos tuvieron que crear nuevas categorías de recuerdo, de pasado y de memoria. Cuando hoy se apela a la categoría de "pueblos originarios" se alude, nuevamente, a la misma construcción historiográfica dominante, que hace de lo más antiguo algo más legítimo por derecho de precedencia. Pero eso supone una única corriente temporal, donde nos ubicamos todos. Y eso recuerda fuertemente los postulados de la "historia universal". ¿Cómo rescatamos o recuperamos entonces los otros recuerdos, los que no tienen legitimidad a veces, ni siquiera en el seno de las mismas sociedades indígenas contemporáneas? Los textos orales recogidos por Gavilán en Isluga y Cariquima (que ella presenta en este mismo dossier) me parecen apasionantes, porque exhiben las dificultades que tienen, precisamente, las propias comunidades para constituir esos relatos y validarlos. 
Frank Salomon realiza una muy acertada crítica a la empresa de construir una etnohistoria foucaultiana. Centra sus comentarios en tres aspectos sobre los cuales me parece importante detenerme: uno, en lo que llama el "fundamento epistemológico" y que tiene que ver con las maneras de entender los discursos; dos, el supuesto carácter unitario de los discursos; y, finalmente, tres, el peso que la sobrevaloración de los discursos tiene sobre las prácticas interdisciplinarias que, precisamente, contribuyeron a darle a los estudios andinos esa característica que los distingue entre otros espacios disciplinarios.

En el primero de los temas, Salomon emplea una fina e irónica analogía entre el tejido de los discursos y la malla de Supermán, elástica hasta cubrirlo todo, impenetrable para proteger lo que cubre e indestructible al punto de sobrevivir a todo ataque. No es esa, ciertamente, la concepción que tengo de los discursos. Por el contrario. Claro que hay una aspiración de homogeneidad, de totalidad, entre quienes tienen el poder de enunciar y producir discursos; pero ello no quiere decir que, puestos a circular y operar, los discursos alcancen tal grado de autonomía y dominio. Cuando se piensa en los espacios de enunciación, en los lugares sociales desde los que se habla, se puede advertir que los discursos resultan ser a menudo fragmentarios y para nada incombustibles o impenetrables. Por ello propuse el empleo de dos conceptos que, muy ligados, apuntan a planos o niveles distintos. El de discurso, que lo entendí como los marcos más amplios que permiten hablar sobre algo, que están construidos frecuentemente a partir de categorías epistémicas y ontológicas y que son articulaciones de poder; y el de discursividades, que resultan ser los modos concretos, historizables, en las que los discursos que operan en las sociedades toman forma, son aplicados de manera singular aquí o allá. En el juego entre ambos niveles aparecen los muchos discursos y discursividades en tensión, antagónicos, que proponen miradas y aproximaciones (también experiencias) diferentes. Ahora bien, estoy de acuerdo, cierta dimensión de los discursos efectivamente puede operar como la malla de Supermán, impidiéndonos ver qué hay bajo ella, sobre todo cuando se pretende leer directamente los documentos, dejando fuera la dimensión discursiva de esos textos. Pero eso ocurre cuando se toma a estos últimos como superficies planas, sin considerar que son resultado de muchas operaciones previas y simultáneas de significación. Es por ello que propongo metodológicamente un camino de "despeje de capas discursivas" que, para seguir con Supermán, permite ir despojándolo de sus muchas protecciones. Finalmente lo que queda es un superhéroe aspirando a ser humano.

La dimensión epistemológica de los discursos, resaltada igualmente por mi colega, me lleva a plantear dos cuestiones más. Una es la del cambio de episteme que provocó la secuela de 1492. Es cierto y en eso tiene toda la razón. El proceso de expansión e invasión de Europa hacia América provocó profundos cambios, que estuvieron muy lejos de ser "apacibles". Si bien no acentué una cierta violencia en las transformaciones internas de las epistemes europeas en juego en la época, ella me resulta evidente en las muchas luchas ocurridas para imponer uno u otro discurso, para construir las diferencias entre europeos e indios, para nombrar a unos y otros.

Respecto del carácter unitario que tendrían los discursos, me parece importante señalar que eso ocurre, probablemente, en diversos estudios que han utilizado los planteamientos de Michel Foucault. Mi perspectiva, sin embargo, es que la propuesta de ese autor permite advertir su preocupación por la existencia simultánea de muchos discursos, en todo momento ${ }^{3}$. Toda sociedad en cualquier momento de su historia social será algo así como un coro polifónico, donde es cierto que algunas voces se imponen e intentan acallar a otras, pero en el cual también se pueden advertir otras, más en sordina, que intentan a su vez cantar otras melodías. Coincido plenamente con Salomon cuando llama la atención sobre los peligros de construir análisis que reducen esa riqueza polifónica a un único sonido o discurso. La supuesta flexibilidad de malla de Supermán que le permitiría recubrir todo bajo un manto único, homogeneizador. Ciertamente hay que luchar contra esas generalizaciones o simplificaciones.

Sobre el tercer punto destacado por Salomon, el de las prácticas interdisciplinarias, no puedo sino coincidir completamente con él. Me parece que el desarrollo de los estudios andinos y con ello el de la etnohistoria, tiene uno de sus pilares precisamente en esa forma de construir conocimiento. $\mathrm{La}$ interdisciplinariedad molesta, a veces, a algunos de nuestros colegas que quisieran ver tal vez fronteras más diferenciadas entre unos y otros. Mi posición es que la riqueza del conocimiento que poseemos actualmente sobre las sociedades andinas resulta gracias a que en estos estudios han confluido la antropología, la historia, la arqueología, la linguiística, 
la historia del arte y la teoría crítica literaria (la lista es mayor, por supuesto). Si en Gente de la Tierra de Guerra el peso mayor está dado por el análisis de la escritura, en detrimento de la arqueología o de la antropología, se debe a que siempre entendí ese libro como una etapa metodológica en la construcción de nuestro aprendizaje sobre las sociedades andinas; como una puesta al día respecto de nuestras estrategias metodológicas para entender cómo hemos estado leyendo los documentos coloniales. Pero, superado ese momento, la interdisciplinariedad resulta no solo central como estrategia, sino casi como una vía obligada.

Mi afirmación anterior tiene que ver con un aspecto que considero de enorme importancia. El estudio de los sistemas de registro andinos sugiere que su funcionamiento requirió de semióticas complejas, multisensoriales. Por semióticas complejas me refiero a que la emisión y la recepción de los mensajes o discursos utilizaban de manera simultánea diversos lenguajes semióticos. La lectura de algunos quipus, por ejemplo, tal como lo han planteado algunos autores ${ }^{4}$ pareciera haberse realizado en un contexto de bailes y música, así como de determinados movimientos corporales. Tenemos evidencia, asimismo, de que el arte rupestre requería de la realización de diversos rituales para lograr su eficacia simbólica y comunicacional (Bollaert 1975 [1860]); y recientemente hemos demostrado que los vínculos de los lenguajes visuales de los qeros y de las narrativas orales, plantean que sus imágenes apelaban también a los procedimientos verbales (Martínez y Martínez 2013), entre otros varios ejemplos posibles. Por otra parte, si las semióticas complejas apelan a la complementariedad y -tal vez- redundancia para que se produzca su enunciación y recepción, la multisensorialidad parece apelar a la simultaneidad sensorial: músicos cuyos movimientos y vestuarios también significan; espacialidades que se llenan de colores y olores; qeros que son mirados pero que también son recipientes de bebidas rituales, son algunos de los ejemplos que nos plantean la necesidad de abordar el análisis de los procesos de enunciación prehispánicos y coloniales y del uso de los sistemas de soporte y comunicación desde la perspectiva de lo multisensorial. La multisensorialidad es igualmente un enfoque teórico que obliga a repensar interdisciplinariamente los materiales con que hemos estudiado, desde hace décadas, a las sociedades andinas, y esto incluye las oralidades. De manera tal que me parece que la comprensión de los lenguajes y de los sistemas comunicacionales andinos requiere metodológicamente una aproximación integrada por diversas disciplinas.

Para cerrar. ¿Bakhtin o Foucault? Trabajando con los materiales andinos, los qeros, el arte rupestre, las teatralidades, el orden de los discursos coloniales europeos se desarma, y sus metodologías de estudio se revelan útiles pero insuficientes. ¿Mejor la polifonía discordante bakhtiniana, como lo propone Salomon? Puede ser. Me atrae la idea del desorden, de muchas voces hablando simultáneamente. Me gustaría, sin embargo, inclinarme por una tercera opción. ¿Cómo pensar estas sociedades desde otras posiciones teóricas, en diálogo con Foucault y Bakhtin, pero capaz también de dar cuenta de sus propias especificidades?

No puedo sino coincidir también con varios de los aportes de Francisco Gil, que enriquecen aún más mi aproximación a los lipes, tanto en lo propuesto en este libro como en mis trabajos anteriores sobre esas mismas poblaciones. Sus comentarios se centran, sobre todo en una reflexión acerca de las denominaciones contradictorias que se encuentran en los documentos del siglo XVI sobre los habitantes del altiplano de Lípez. Creo que en esa reflexión, Gil García avanza bastante más allá de lo que yo mismo propuse, agregando matices y sutilezas que, debo reconocerlo, se me escaparon cuando hice ese análisis. Gil García apunta a un aspecto que me parece importante discutir aquí, porque tiene una más amplia repercusión en los análisis etnohistóricos sobre cualquier sociedad que estudiemos. Después de revisar, y descartar, que las contradicciones se deben a que se trataba, posiblemente, de colectivos distintos o a que se aplicaron en épocas cronológicamente distintas (todo lo cual es posible, pero no lo central), sugiere que una de las posibilidades de interpretar las contradicciones es la de una cierta incomprensión cultural, sobre todo por parte de los españoles, básicamente en lo que se refiere a la interpretación de las prácticas de los otros a partir de sus propios parámetros de valorización cultural, en especial acerca de las prácticas productivas (agropastoriles, de caza y recolección).

Me parece importante señalar que efectivamente en la documentación colonial es frecuente encontrar muestras y pruebas de incomprensión acerca de las distintas experiencias y valorizaciones culturales. Esta es una condición que a menudo tienen los documentos coloniales, en especial los más tempranos, 
y metodológicamente es algo que siempre debe analizarse. Si bien las que más destacan, porque tienen el predominio de la palabra escrita, son las europeas, no es menos cierto que del lado indígena también se produjeron incomprensiones. Y el análisis que hace Gil García sobre los "presentes" que habrían llevado los lipes al virrey Francisco de Toledo es esclarecedor. No se trataría de signos de pobreza, sino, por el contrario, presentes exóticos muy valorados en el seno de las sociedades andinas preeuropeas, ignorantes aparentemente de que los españoles no sabrían comprender su real valor. Eso es cierto, y ha sido un recurso interpretativo al que muchos hemos recurrido en algún momento de nuestras investigaciones; pero no podemos dejar de lado lo que señaló tempranamente John Murra (2002) ${ }^{5}$ acerca de la capacidad de diversos europeos de percibir y entender correctamente las diferencias y las prácticas de los andinos. El licenciado Polo, mencionado en el comentario de Frank Salomon, es un claro ejemplo de esto. Y los tempranos alegatos judiciales sobre la legitimidad de unas u otras autoridades, que utilizaron el derecho sucesorio patrilineal para imponerse, muestra igualmente que desde el lado andino operó también una comprensión acerca del otro, de los europeos y sus prácticas. Considerando entonces ambos polos de la comprensión-incomprensión, me parece que el desafío no es tanto el determinar por qué se formuló una u otra afirmación (no quiero desconocer que eso es muy importante también), sino el poner de relieve las tramas de prácticas y discursos, de luchas, de acomodamientos, de aceptaciones y rechazos, que siempre y en cualquier momento operan al interior de dos sociedades en la que una de ellas está intentando imponerse sobre la otra.

Los comentarios de Vivian Gavilán me parecieron extremadamente interesantes, porque ella se atrevió a revisar sus propios materiales a la luz de algunas de las propuestas de Gente de la Tierra de Guerra. Y lo que muestra, sobre todo respecto de las prácticas de construir/descontruir, exhibir u ocultar las identidades, de vivirlas en definitiva, me plantea muchos problemas teóricos. Porque ella destaca continuidades que es necesario explicar, entre los habitantes del altiplano de Lípez y los actuales habitantes del altiplano aymara de Isluga y Cariquima.

Finalmente, ¿Qué más decir ante los comentarios recibidos, los debates abiertos, los comentarios críticos y enriquecedores, y también los elogios? Ante todo, expresar mis agradecimientos a los colegas Guillaume Boccara, Frank Salomon, Francisco Gil García y Vivian Gavilán, por el debate abierto. Espero haber estado a su altura en mis respuestas $\mathrm{y}$, sobre todo, en haber contribuido al debate que ellos propusieron que, estoy convencido, va mucho más allá que los reducidos límites de un libro y de la zona andina. Creo que sus planteamientos tienen que ver con una reflexión y discusión que nos involucra a todos cuantos seguimos dedicándonos a tratar de mejor conocer y entender a las sociedades americanas y a las sociedades oprimidas y colonizadas.

\section{Referencias Citadas}

Aschero, C. 1999. El arte rupestre del desierto puneño y el noroeste argentino. En Arte Rupestre en los Andes de Capricornio, editado por J. Berenguer y F. Gallardo, pp. 97-135. Museo Chileno de Arte Precolombino y Banco de Santiago, Santiago.

Boccara, G. 2013. La apoteosis de la antropología histórica y el desafío poscolonial. Chungara Revista de Antropología Chilena 45:523-531.

Curatola, M. y J.C. De la Puente 2013. Contar concertando: quipus, piedritas y escritura en los Andes coloniales. En El Quipu Colonial. Estudios y Materiales, editado por M. Curatola y J.C. De la Puente, pp. 193-243. Pontificia Universidad Católica del Perú, Lima.

Foucault, M. 1979. Microfísica del Poder. Ediciones de La Piqueta, Madrid.

Gallardo, F., C. Sinclaire y C. Silva 1999. Arte rupestre, emplazamiento y paisaje en la cordillera del desierto de Atacama.
En Arte Rupestre en los Andes de Capricornio, editado por J. Berenguer y F. Gallardo, pp. 57-96. Museo Chileno de Arte Precolombino y Banco de Santiago, Santiago.

Gavilán Vega, V. 2013. De la administración de poblaciones y de etnicidades en los Andes del sur: las dos caras de la colonización ayer y hoy. Chungara Revista de Antropología Chilena 45:543-551.

Gil García, F.M. 2013. Los intereses creados. Los lipes en las clasificaciones coloniales del siglo XVI. Chungara Revista de Antropología Chilena 45:533-542.

Hernández Llosas, M.I. 2006. Inkas y españoles a la conquista simbólica del territorio Humahuaca: sitios, motivos rupestres y apropiación cultural del paisaje. Boletín del Museo Chileno de Arte Precolombino 11:9-34.

Martínez C., J.L. y M. Arenas 2009. Problematizaciones en torno al arte rupestre colonial en las áreas Centro Sur y Meridional 
Andina. En Crónicas sobre la Piedra. Arte Rupestre de las Américas, editado por M. Sepúlveda, L. Briones y J. Chacama, pp. 129-140. Ediciones Universidad de Tarapacá, Arica.

Martínez C., J.L. y P. Martínez 2013. Narraciones andinas coloniales. Oralidad y visualidad en los Andes. Journal de la Société des Americanistes 99 (2), en prensa.

Medinacelli, X. y M. Inch (coord.) 2010. Pleitos y Riqueza. Los Caciques Andinos en Potosí del Siglo XVII. Transcripción y Estudios del Expediente de don Diego Chambilla contra los Bienes de su Administrador. Ediciones Archivo y Biblioteca Nacionales de Bolivia, Sucre.

Murra, J. 1978. La correspondencia entre un "capitán de mita" y su apoderado en Potosí. Historia y Cultura 3:45-58.

. _ _ 2002 [1970]. Las investigaciones en etnohistoria andina y sus posibilidades en el futuro. En El Mundo Andino. Población, Medio Ambiente y Economía, pp. 445-470, Instituto de Estudios Peruanos-Pontificia Universidad Católica del Perú, Lima.

. _ _ 2002 [1973]. Las etnocategorías de un khipu estatal. En El Mundo Andino. Población, Medio Ambiente y Economía, pp. 248-260. Instituto de Estudios Peruanos-Pontificia Universidad Católica del Perú, Lima.

_ _ _ 2002 [1991]. Nos hazen mucha ventaja: la percepción europea temprana de los logros andinos. En El Mundo Andino.
Población, Medio Ambiente y Economía, pp. 25-40, Instituto de Estudios Peruanos-Pontificia Universidad Católica del Perú, Lima.

Pease G.Y., F. 1978. Las visitas como testimonio andino. En Historia, Problema y Promesa. Homenaje a Jorge Basadre, vol. I, editado por F. Miro Quesada, F. Pease y D. Sobrevilla, pp. 437-453. Universidad Católica del Perú, Lima.

- _. _ 1995. Las Crónicas y los Andes; Fondo de Cultura Económica-Universidad Católica del Perú, Lima.

Platt, T., T. Bouysse-Cassagne y O. Harris 2006. Qaraqara-Charka. Mallku, Inka y Rey en la Provincia de Charcas (Siglos XV-XVII). Instituto Francés de Estudios Andinos-Plural editores-University of St Andrews-University of London-Interamerican FoundationFundación Cultural del Banco Central de Bolivia, La Paz.

Rostworowski, M. 1983. Estructuras Andinas del Poder. Ideología Religiosa y Política. Instituto de Estudios Peruanos, Lima.

Salomon, F. 1994. La textualización de la memoria en la América Andina: una perspectiva etnográfica comparada. América Indígena 54:229-261.

_ _ _ 2013. Supermán es más super cuando se quita la malla. Chungara Revista de Antropología Chilena 45:515-522.

Wachtel, N. 1976. Los Vencidos. Los Indios del Perú frente a la Conquista Española (1530-1570). Alianza Editorial, Madrid.

\section{Notas}

AHP, Cajas Reales 1, f.58r, año 1559.

2 Entre los varios trabajos que se refieren a la revalorización de los documentos burocráticos para obtener, desde allí, testimonios andinos más directos, y que transformaron profundamente los estudios andinos, véanse Murra (2002 [1970]) y Pease (1978).
3 Es lo que aparece remarcado, claramente, en su curso del 7 de enero de 1976; 1979.

4 Esto fue planteado, por ejemplo, en Curátola y De la Puente (2013).

5 Véase, en especial, su artículo "Nos hazen mucha ventaja: la percepción europea temprana de los logros andinos". 